ORIGINAL ARTICLE

\title{
Mortality in the UK industrial silica sand industry: 2. A retrospective cohort study
}

\author{
T P Brown, L Rushton
}

Occup Environ Med 2005;62:446-452. doi: 10.1136/oem.2004.017731

See end of article for authors' affiliations

.....................

Correspondence to:

Dr T P Brown, Medical

Research Council Institute

for Environment and Health, 94 Regent Road, Leicester LE1 7DD, UK; tpb3@le.ac.uk

Accepted 1 February 2005

\begin{abstract}
Aims: To evaluate the mortality experience of a cohort of employees in the UK silica sand industry exposed to respirable crystalline silica (RCS).

Methods: A retrospective cohort mortality study followed all workers to 2001 with at least one year's employment at one of seven UK silica sand producing quarries between 1950 and 1986. Each worker was assigned a job category and cumulative exposure to RCS was estimated using a job-exposure matrix. Results: A total of 764 deaths were identified in 2703 cohort members. The overall mortality rate for the cohort was lower than would be expected in the general population. Mortality from circulatory and respiratory disease was also less than expected, but death due to pneumoconiosis was slightly raised (two deaths). Mortality from all cancers was slightly decreased. Mortality was not raised in any job category. Cancer mortality was raised at one quarry due to a significant increase in lung (standardised mortality rate (SMR) 162.0, 95\% Cl 113.5 to 224.3) and bladder (SMR 366.5, 95\% Cl 167.6 to 695.7) cancers. Mortality from lung cancer and other causes did not show a trend with cumulative exposure to RCS.

Conclusions: This study did not show any consistent relation between RCS exposure (in the absence of other known carcinogens) and the development of lung cancer. This contrasts with a number of studies that have shown positive findings in similar and related industries.
\end{abstract}

O ccupational exposures to respirable crystalline silica (RCS) occur in a variety of industries and occupations because of its common natural occurrence and the wide use of materials and products that contain it. Occupational exposure to RCS dust is a potentially serious but preventable health hazard. The major health hazards associated with exposure are silicosis, pulmonary tuberculosis, chronic bronchitis, and chronic obstructive pulmonary disease. Silicosis has been a recognised disease process for over 400 years, and many studies have shown a link between cumulative exposure to RCS and the incidence or prevalence of radiographic silicosis in various industries. ${ }^{1-11}$ Recent epidemiological studies have also reported increased incidence of, and mortality from, extrapulmonary diseases such as scleroderma, rheumatoid arthritis, other autoimmune disorders, and renal disease. ${ }^{9}$

Lung cancer is also associated with exposure to RCS, but this is more contentious. In 1997, a working group of the International Agency for Research on Cancer (IARC) published a monograph classifying crystalline silica inhaled in the form of quartz or cristobalite from occupational sources as carcinogenic to humans. ${ }^{12}$ In making the overall evaluation the working group noted that carcinogenicity was not detected in all industrial circumstances, and may be dependent on inherent characteristics of the crystalline silica or on external factors affecting its biological activity or distribution of its polymorphs. The IARC assessment sparked considerable debate and there remains scientific controversy over whether inhaling crystalline silica dust increases the risk of developing lung cancer in humans.

During 1986 the UK Health and Safety Executive (HSE) collected details of workers employed, or formerly employed, by a large UK industrial sand company. The HSE collected death and cancer registration information, but never published any analysis of the data. A description of the industry and the development of a job-exposure matrix (JEM) were described in a previous paper. ${ }^{13}$ This paper describes the mortality patterns of the cohort.

\section{METHODS}

\section{Cohort definition}

The original cohort contained details of 4749 (4185 men, 522 women, 42 sex unknown) employees and former employees at seven quarries belonging to the company before 1986 . The entry date into the cohort for the current analysis was defined as 1 January 1950. Individuals who had left or died before $1950(n=248)$ and short term workers, those with less than one year's employment $(n=1590)$, were excluded from the cohort. If an individual worked for less than a year, left, and then subsequently worked for more than a year, the person-years at risk (pyr) were counted from the second period of employment. If an individual worked for more than a year, left, and then returned for periods of work for less than a year, these other periods contributed, in full, to the pyr. An additional 208 workers had inadequate data for tracing or work history, leaving 2703 subjects (2365 men, 338 women) available for analysis. The numbers from each quarry reflected the size of the operation there, varying from 87 and 124 at quarries 2 and 5 respectively, to 623 and 712 at quarries 4 and 7 , respectively.

\section{Retrospective exposure assessment}

Individuals were coded by the HSE with the assistance of the company's industrial hygienist to the first known job in which they had been employed for at least three months. Company records were used to assign each individual to one of 16 job categories; but for some others long serving workers were consulted (numbers unknown); it is possible that in some cases not all the jobs a person did would have been remembered.

Cumulative exposure to RCS was estimated using a specially developed job-exposure matrix (JEM). ${ }^{13}$ Exposure

Abbreviations: $\mathrm{Cl}$, confidence interval; $\mathrm{COPD}$, chronic obstructive pulmonary disease; JEM, job-exposure matrix; NMRD, non-malignant respiratory disease; RCS, respirable crystalline silica; SMR, standardised mortality ratio 


\begin{tabular}{|c|c|c|c|c|}
\hline Variable with levels & Lung cancers & $\begin{array}{l}\text { Non-malignant } \\
\text { respiratory disease }\end{array}$ & All causes & Person-years at risk \\
\hline \multicolumn{5}{|c|}{$\begin{array}{l}\text { Cumulative exposure to } \\
\text { respirable crystalline silica }\end{array}$} \\
\hline$<0.13$ & 19 & 19 & 168 & 16975.6 \\
\hline $0.13-<0.40$ & 21 & 19 & 175 & 15907.1 \\
\hline $0.40-<1.00$ & 21 & 21 & 171 & 13909.6 \\
\hline$\geqslant 1.00$ & 17 & 24 & 181 & 17114.6 \\
\hline \multicolumn{5}{|l|}{ Quarry } \\
\hline 1 & 5 & 3 & 29 & 3376.6 \\
\hline 2 & 5 & 3 & 29 & 2525.0 \\
\hline 3 & 14 & 12 & 117 & 14704.4 \\
\hline 4 & 7 & 29 & 227 & 18405.3 \\
\hline 5 & 4 & 0 & 23 & 3003.0 \\
\hline 6 & 8 & 11 & 90 & 13049.3 \\
\hline 7 & 38 & 33 & 249 & 21098.1 \\
\hline \multicolumn{5}{|l|}{ Calendar period } \\
\hline $1950-1979$ & 20 & 18 & 187 & 29979.8 \\
\hline $1980-1984$ & 18 & 13 & 128 & 11287.9 \\
\hline $1985-1989$ & 15 & 13 & 115 & 11026.3 \\
\hline $1990-2001$ & 28 & 47 & 334 & 23867.7 \\
\hline \multicolumn{5}{|l|}{ Attained age } \\
\hline-49 & 2 & 3 & 72 & 10290.3 \\
\hline $50-59$ & 20 & 7 & 134 & 21868.6 \\
\hline $60-69$ & 39 & 27 & 212 & 19838.9 \\
\hline $70-74$ & 11 & 16 & 130 & 9308.4 \\
\hline $75-79$ & 8 & 9 & 99 & 7611.8 \\
\hline \multirow{2}{*}{\multicolumn{5}{|c|}{$\begin{array}{l}\text { Period from first employment } \\
\text { (years) }\end{array}$}} \\
\hline & & & & \\
\hline $0-5$ & 34 & 22 & 266 & 5564.0 \\
\hline $5-9$ & 25 & 29 & 219 & 25833.8 \\
\hline $10-19$ & 14 & 29 & 184 & 29037.6 \\
\hline$>=20$ & 8 & 11 & 95 & 15726.3 \\
\hline \multicolumn{5}{|l|}{ Employment status } \\
\hline In post & 6 & 2 & 25 & 9257.7 \\
\hline Left & 75 & 89 & 739 & 66904.0 \\
\hline \multicolumn{5}{|l|}{$\begin{array}{l}\text { Year of commencing } \\
\text { employment }\end{array}$} \\
\hline-1949 & 14 & 26 & 199 & 9351.9 \\
\hline $1950-1959$ & 22 & 21 & 186 & 12642.3 \\
\hline $1960-1969$ & 24 & 32 & 225 & 26731.3 \\
\hline $1970-1986$ & 21 & 12 & 154 & 27436.2 \\
\hline \multicolumn{5}{|l|}{ Sex } \\
\hline Men & 77 & 88 & 727 & 67124.2 \\
\hline \multirow{2}{*}{ Total } & 4 & 3 & 37 & 9037.5 \\
\hline & 81 & 91 & 764 & 76161.7 \\
\hline
\end{tabular}

levels were assigned to workers on the basis of the job they held, the quarry, and calendar period in which they worked. Briefly, 3012 personal and static RCS samples, collected between 1978 and 2000, were combined into a single dataset, since no statistical differences were found by analysis of variance $(p>0.05)$ between the two types of measurement across quarries, jobs, and years. Regression models were fitted to the data that estimated the dependence of the mean exposure level on job, quarry and year, and were used to give adjusted mean exposure levels. The differences between these means were then tested statistically for each quarry and year to define the similar categories. Five categories of quarry (quarry 1; quarries 2 and 3; quarry 4; quarries 5 and 6; quarry $7)$, and three time periods (1978-85; 1986-94; 1995-2000) were defined.

No dust measurements were available before 1978 . Therefore, exposure levels for each job category and quarry group in the JEM were estimated using linear regression of the available data and extrapolation back to 1950 by assuming: (a) exposure levels had decreased linearly over time between 1950 and 1978; (b) exposure levels between 1950 and the end of the 1970s were the same as in 1978; and (c) exposure levels were midway between (a) and (b). For each option the time periods in the JEM were taken as fiveyear calendar periods up to 1975 .

For each worker with a complete work history, the number of years in each of the time periods was calculated. The cumulative exposure was then calculated by multiplying these by the exposure level for the relevant job, quarry group, and time period. Cumulative exposure was categorised into four groups, which contained similar numbers of deaths, using option (a) as the basis for categorisation.

\section{External comparison: SMR analysis}

The cohort was followed up for the years 1950-2001 through the National Health Service Central Register (NHSCR) of the Office for National Statistics (England and Wales) and the General Register Office for Scotland (GROS). Expected numbers of deaths were calculated from serial mortality rates for England and Wales, and Scotland, applied to similar defined distributions of person-years at risk (pyr) generated by the data. Workers entered the pyr one year after 1 January 1950 or one year after commencing employment, whichever was the later. They left the pyr on the closing date of the study (31 December 2001), the date of death, date of emigration, or date last known alive, whichever was the 
earlier date. Standardised mortality ratios (SMRs) were calculated as the ratio of observed deaths to expected deaths, expressed as a percentage. These procedures were carried out using OCMAP-Plus. ${ }^{14}$

\section{Internal analyses}

Analysis for exposure-response trends were conducted, using Poisson regression modelling to adjust for confounders, on a slightly smaller sub-cohort (2272) with complete data on job and dates of starting and leaving, and focused on lung cancer and non-malignant respiratory diseases (NMRD), these being previously related to exposure to RCS. Cases of lung cancer were selected as those deaths for which any part of the death certificate (Ia, Ib, Ic, or II) would be coded (ICD 7-9: 162; ICD 10: C33-34). This approach introduced four further cases of lung cancer not available to the SMR analyses.

A number of variables were considered to have the potential for influencing mortality within the cohort: attained age, calendar period, year of commencing employment, time since first employment, employment status (still employed/left employment), and estimated cumulative exposure to RCS. Variables were characterised into a number of levels such that at least one death was observed at each level of each variable. The categories are shown in table 1 . These variables are time dependent (with the exception of quarry and sex) and the analysis allows subjects to contribute pyr to concurrent categories.

The STATA computer program was used to provide pyr and numbers of deaths for all combinations of all levels of the selected variables, and to carry out Poisson regression modelling. ${ }^{15}$

\section{RESULTS}

Between 1951 and 2001 there were 764 deaths in the cohort. Table 2 shows observed and expected numbers of all causes and selected causes of death. There were no significant excesses for any specific diseases. Just under half the deaths were due to circulatory diseases $(351,45.9 \%)$, and under a third from cancer $(218,28.5 \%)$. Mortality from all causes was significantly decreased in both men $(\mathrm{SMR}=90.0,95 \% \mathrm{CI}$ 83.6 to 96.8 ) and women ( $\mathrm{SMR}=70.0,95 \%$ CI 49.3 to 96.4 ). Mortality from circulatory diseases was significantly reduced in men $(\mathrm{SMR}=89.6,95 \%$ CI 80.3 to 99.8$)$, with a decrease in death from general circulatory disease categories and cerebrovascular disease $(\mathrm{SMR}=61.0,95 \% \mathrm{CI} 43.6$ to 83.1 ). A reduction was also seen in women. A slight reduction in respiratory disease death was seen in men, especially chronic obstructive pulmonary disease (COPD). A non-significant excess in pneumoconiosis was seen in men, although based on only two deaths; one was confirmed as silicosis, the other unspecified pneumoconiosis. There were two other deaths where unspecified pneumoconiosis was mentioned as a contributory cause of death; in both cases the underlying cause of death was COPD. No cases of tuberculosis were observed. Of the other diseases of interest, there were two deaths from rheumatoid arthritis (RA), two from acute renal disease (ARD) (ICD-9 580, 581, 584), and three from chronic renal disease (CRD) (ICD-9 582, 583, 585-587). RA was mentioned as a contributory cause to four other deaths, ARD to one other, and CRD to 20 others. Systemic lupus erythematosus was mentioned once.

There was a small deficit of deaths from malignant neoplasms in both men and women. Mortality from pancreatic cancer was significantly reduced ( SMR $=21.6,95 \% \mathrm{CI}$ 2.6 to 78.0 ). Genitourinary cancer deaths in men were slightly higher than expected, as a result of the $65 \%$ increase in mortality from bladder cancer ( SMR $=164.7,95 \%$ CI 90.0 to 276.4). Mortality from lung cancer in men was as expected, whereas among women there was almost a 50\% excess, although the latter was based on only four deaths. The mean age at death for lung cancer was 64.6 years (SD 8.1 years), range 43.3-80.1 years.

Table 3 shows observed and expected numbers of deaths from all causes, NMRD, all cancers, and lung cancer by quarry. The majority of deaths occurred among workers at quarries $7(249,32.6 \%)$ and $4(228,29.8 \%)$. All cause mortality was significantly reduced at quarries 4 and 5 , the former because of significant decreases in all cancers and lung cancer, and also COPD ( SMR $=35.8,95 \%$ CI 9.8 to 91.6). At quarry 7 the SMR for all cancers approached significance largely as a result of excesses of lung cancer and also bladder cancer $(S M R=366.5,95 \%$ CI 167.6 to 695.7$)$. A significant proportion of both the lung ( SMR $=197.6,95 \%$ CI 117.1 to 312.3) and bladder ( $\mathrm{SMR}=671.3,95 \%$ CI 269.9 to 1383.3 ) cases at quarry 7 were first employed between 1950 and 1959, and worked for less than five years (lung: SMR $=202.7,95 \%$ CI 115.8 to 329.1 ; bladder: $\mathrm{SMR}=685.7,95 \%$ CI 251.7 to 1492.5). However, there was no specific trend between mortality and date of hire or length of employment.

Mortality by first known job was difficult to interpret because of the small number of deaths in some categories. There were no significant excesses for any specific disease in any job category. Both cases of pneumoconiosis occurred in dry/dryer workers ( $S M R=3334.9$; 95\% CI 427.7 to 12769.7). Lung cancer mortality was only slightly raised in a number of categories (site maintenance, workshop, brickworks/ wet, dry/other, laboratory technician, other driver, and brickworks/driver job).

\section{Internal comparisons}

Cumulative RCS exposure among cohort members ranged from less than 0.01 to $23.21 \mathrm{mg} / \mathrm{m}^{3}$-years. The geometric mean was $0.31 \mathrm{mg} / \mathrm{m}^{3}$-years (geometric standard deviation 5). Table 4 provides relative risks of mortality for lung cancer and NMRD by categories of cumulative exposure to RCS. Risks are shown relative to a baseline risk of unity for workers (pyr) in the lowest exposure category. The table summarises the relative risks after adjusting for age (first SMR column); and after additional adjustment for period from first employment, employment status (still employed/ left employment), year of starting employment, and quarry. No statistically significant trends across the four exposure categories were found. There are no statistically significant excesses in any of the categories and the patterns of risk are also unclear.

Analysis of cumulative exposure to RCS, with employment histories lagged by 10 or 15 years (that is, for each period of follow up, employment history in the most recent 10 or 15 years is ignored) gave similar results. It should be noted that half the cohort had less than 10 years service, as did half the lung cancer cases.

Sensitivity analysis was carried out to determine whether the various methods used to assess historical exposure (1950-78) gave different estimates of cumulative exposure, and whether this had any effect on the mortality results. For all disease groups, similar trends in the SMRs were seen across the exposure categories irrespective of the option used to calculate exposure, although the magnitude of the SMRs differed. Assuming that the levels between 1950 and 1978 had not changed had the effect of reducing the number of deaths in the top two exposure categories and increasing those in the bottom two categories.

\section{DISCUSSION}

This paper describes the analysis of mortality of a cohort of industrial silica sand workers employed at seven UK quarries between. The cohort, like those of US industrial sand workers, ${ }^{16}{ }^{17}$ is valuable for studying the relation between 


\begin{tabular}{|c|c|c|c|c|c|c|}
\hline \multirow[b]{2}{*}{ Cause of death } & \multicolumn{3}{|l|}{ Men } & \multicolumn{3}{|l|}{ Women } \\
\hline & Observed & Expected & SMR $(95 \% \mathrm{Cl})$ & Observed & Expected & SMR $(95 \% \mathrm{Cl})$ \\
\hline All causes & 727 & 807.8 & $90.0(83.6$ to 96.8$)$ & 37 & 52.9 & 70.0 (49.3 to 96.4$)$ \\
\hline All circulatory diseases & 334 & 372.8 & 89.6 (80.3 to 99.8$)$ & 17 & 20.7 & $82.2(47.9$ to 132.0$)$ \\
\hline Ischaemic heart disease & 231 & 247.3 & $93.4(81.7$ to 106.3$)$ & 7 & 10.5 & 66.8 (26.8 to 137.6$)$ \\
\hline Other heart disease & 103 & 125.5 & 82.1 (67.0 to 99.5$)$ & 10 & 10.2 & 98.0 (47.0 to 180.0 ) \\
\hline All respiratory diseases & 88 & 96.9 & $90.8(72.8$ to 112.0$)$ & 3 & 5.8 & 51.6 (10.6 to 151.0$)$ \\
\hline COPD & 21 & 26.1 & 80.6 (49.9 to 123.2 ) & & & \\
\hline Pneumoconiosis & 2 & 1.4 & $148.2(17.9$ to 535.4$)$ & & & \\
\hline Other respiratory & 65 & 68.2 & $95.3(73.6$ to 121.0$)$ & 3 & 5.1 & 58.8 (12.1 to 172.0$)$ \\
\hline All genitourinary diseases & 9 & 9.1 & $98.6(45.1$ to 187.2$)$ & & & \\
\hline All cancers & 203 & 221.6 & $91.6(79.5$ to 105.1$)$ & 15 & 17.1 & 87.7 (49.1 to 144.7 ) \\
\hline Gastrointestinal cancer & 50 & 65.7 & 76.1 (56.5 to 100.3 ) & 2 & 4.1 & 49.4 (6.0 to 178.3$)$ \\
\hline Oesophagus & 11 & 9.2 & 119.4 (29.6 to 213.7$)$ & 1 & 0.4 & 230.7 (5.8 to 1285.3$)$ \\
\hline Stomach & 18 & 17.7 & $101.6(60.2$ to 160.6$)$ & & 0.7 & \\
\hline Large intestine & 16 & 14.8 & 107.9 (61.7 to 175.2$)$ & & 1.3 & \\
\hline Rectum & 5 & 9.6 & 52.0 (16.9 to 121.3$)$ & 1 & 0.5 & 187.4 (4.7 to 1044.0$)$ \\
\hline Pancreas & 2 & 9.3 & $21.6(2.6$ to 78.0$)$ & & & \\
\hline Lung & 77 & 77.7 & $99.0(78.2$ to 123.8$)$ & 4 & 2.8 & 145.2 (39.6 to 371.8 ) \\
\hline Breast & & & & 4 & 3.9 & 101.8 (27.7 to 260.7 ) \\
\hline Genitourinary & 34 & 31.0 & 109.7 (76.0 to 153.3 ) & 2 & 2.9 & 69.8 (8.4 to 252.1$)$ \\
\hline Prostate & 16 & 16.8 & 95.3 (54.5 to 154.8 ) & & & \\
\hline Bladder & 14 & 8.5 & $164.7(90.0$ to 276.4$)$ & & & \\
\hline Kidney & 4 & 4.8 & 84.0 (22.9 to 215.2$)$ & & & \\
\hline Brain & 4 & 5.6 & 71.0 (19.3 to 181.7$)$ & & & \\
\hline Lymphohaematopoietic & 14 & 14.9 & 93.7 (51.2 to 157.2 ) & 2 & 1.1 & 178.2 (21.6 to 643.7$)$ \\
\hline Non-Hodgkin's lymphoma & 4 & 5.4 & 74.7 (20.4 to 191.3$)$ & 2 & 0.4 & 483.3 (58.5 to 1745.7 ) \\
\hline Multiple myeloma & 6 & 2.9 & 208.3 (76.4 to 453.3 ) & & & \\
\hline Leukaemia & 4 & 5.5 & 73.0 (19.9 to 186.9$)$ & & & \\
\hline
\end{tabular}

silica exposure and lung cancer because, to a large extent, there is unlikely to have been significant exposure to other occupational lung carcinogens which can occur in some silica exposed workers such as coal miners and foundry workers. The cohort is reasonably large (764 deaths, including 81 lung cancer deaths) and has allowed sub-cohort analysis to be

\begin{tabular}{|c|c|c|c|}
\hline Quarry & Observed & Expected & SMR $(95 \% \mathrm{Cl})$ \\
\hline \multicolumn{4}{|c|}{ All causes } \\
\hline 1 & 29 & 31.8 & 91.3 (61.1 to 131.1 ) \\
\hline 2 & 29 & 32.5 & $89.1(59.7$ to 128.0$)$ \\
\hline 3 & 117 & 127.9 & 91.4 (75.6 to 109.6$)$ \\
\hline 4 & 228 & 281.5 & $81.0(70.8 \text { to } 92.2)^{* *}$ \\
\hline 5 & 23 & 38.5 & $59.8(37.9 \text { to } 89.7)^{* *}$ \\
\hline 6 & 90 & 94.1 & 95.6 (76.9 to 117.5$)$ \\
\hline 7 & 249 & 257.4 & 96.7 (85.1 to 109.5$)$ \\
\hline \multicolumn{4}{|c|}{$\begin{array}{l}\text { Non-malignant respiratory } \\
\text { diseases }\end{array}$} \\
\hline 1 & 3 & 3.2 & 94.9 (19.6 to 277.0 ) \\
\hline 2 & 3 & 3.7 & 80.4 (16.6 to 235.0$)$ \\
\hline 3 & 12 & 13.8 & $87.2(45.1$ to 152.0$)$ \\
\hline 4 & 29 & 38.3 & $75.8(50.8$ to 109.0$)$ \\
\hline 5 & 0 & 3.2 & \\
\hline 6 & 11 & 9.5 & 116.0 (57.8 to 207.0$)$ ) \\
\hline 7 & 33 & 31.7 & 104.0 (71.7 to 146.0 ) \\
\hline \multicolumn{4}{|c|}{ All cancers } \\
\hline 1 & 7 & 9.7 & $71.9(28.9$ to 148.1$)$ \\
\hline 2 & 6 & 9.4 & $63.6(23.3$ to 138.4$)$ \\
\hline 3 & 36 & 37.6 & $95.7(67.0$ to 132.4$)$ \\
\hline 4 & 43 & 74.2 & $57.9(41.9 \text { to } 78.0)^{* *}$ \\
\hline 5 & 6 & 9.4 & $63.9(23.4$ to 139.0$)$ \\
\hline 6 & 31 & 27.8 & 111.6 (75.8 to 158.4 ) \\
\hline 7 & 88 & 71.0 & 124.0 (99.4 to 152.8$)$ \\
\hline \multicolumn{4}{|c|}{ Lung cancer } \\
\hline 1 & 5 & 3.3 & 153.3 (49.8 to 357.7 ) \\
\hline 2 & 5 & 3.3 & 151.9 (49.3 to 354.5 ) \\
\hline 3 & 14 & 12.3 & 113.6 (62.1 to 190.5 ) \\
\hline 4 & 7 & 26.1 & $26.8(10.8 \text { to } 55.3)^{* *}$ \\
\hline 5 & 4 & 3.5 & 114.0 (31.1 to 292.0 ) \\
\hline 6 & 8 & 8.6 & 93.6 (40.4 to 184.4$)$ \\
\hline 7 & 38 & 23.6 & 160.8 (113.8 to $\left.220.7^{\star \star}\right)$ \\
\hline
\end{tabular}


Table 4 Relative risk of mortality from lung cancer and non-malignant respiratory disease by levels of cumulative respirable crystalline silica exposure in UK industrial silica sand workers

\begin{tabular}{|c|c|c|c|c|c|}
\hline $\begin{array}{l}\text { Cumulative RCS exposure } \\
\text { (mg/m } \mathrm{m}^{3} \text {-years) }\end{array}$ & $\mathbf{n}$ & $\mathbf{R R}^{*}$ & $(95 \% \mathrm{Cl})$ & RRt & $(95 \% \mathrm{Cl})$ \\
\hline \multicolumn{6}{|l|}{ Lung cancer $\ddagger$} \\
\hline$<0.13$ & 20 & 1.0 & & 1.0 & \\
\hline $0.13-<0.40$ & 21 & 1.24 & (0.66 to 2.34$)$ & 1.14 & $(0.60$ to 2.18$)$ \\
\hline $0.40-<1.00$ & 22 & 1.42 & (0.76 to 2.67$)$ & 1.12 & $(0.58$ to 2.18$)$ \\
\hline$\geqslant 1.00$ & 19 & 0.88 & (0.45 to 1.73 ) & 0.92 & (0.44 to 1.92$)$ \\
\hline$p$ value for trend & & $p=0.79$ & & $p=0.80$ & \\
\hline \multicolumn{6}{|c|}{ Non-malignant respiratory diseases $\S$} \\
\hline$<0.13$ & 19 & 1.0 & & 1.0 & \\
\hline $0.13-<0.40$ & 19 & 1.24 & (0.67 to 2.28$)$ & 1.33 & (0.71 to 2.50$)$ \\
\hline $0.40-<1.00$ & 21 & 1.22 & $(0.65$ to 2.30$)$ & 0.98 & (0.51 to 1.88$)$ \\
\hline$\geqslant 1.00$ & 24 & $\begin{array}{l}1.46 \\
p=0.48\end{array}$ & (0.82 to 2.62$)$ & $\begin{array}{l}1.12 \\
p=0.98\end{array}$ & (0.59 to 2.14$)$ \\
\hline
\end{tabular}

*Analysed simultaneously with attained age.

†Analysed simultaneously with attained age, period from first employment, employment status, year of starting employment, and quarry.

\pm Any part of the death certificate coded to ICD 162 or C33/C34.

§Underlying cause of death coded to ICD 460-519 or J00-J99.

undertaken. Industrial hygiene sampling data over time were available from 1978 to 2001, which enabled historical RCS exposure-response analyses to be conducted.

Overall mortality for the total cohort was below that expected compared to the UK population for the same period. This result was similar to that in a previous analysis of mortality on the cohort carried out by the HSE. ${ }^{18}$ No statistically significant excesses of any specific diseases were observed, although some mortality rates were slightly raised. A significant reduction in mortality from circulatory diseases was observed among men, especially cerebrovascular diseases. Mortality from respiratory diseases was also less than expected, especially COPD.

Mortality from bladder cancer was slightly raised as a result of a significantly increased risk in this cancer at quarry 7. Further analysis of these cases indicated that those who first started work between 1950 and 1959 and for less than five years were at a significantly greater risk. It might be that exposure to another pollutant at the quarry is responsible for this increased risk. This quarry previously had a brickworks on site, up until the mid-1970s, making sand-lime bricks, and exposure to other carcinogens (including pigments, dyes, and polycyclic aromatic hydrocarbons) during their manufacture might have influenced the bladder cancer mortality, and needs further investigation.

Mortality from respiratory diseases was less than expected, especially COPD. However, the risk for NMRDs increased with cumulative exposure to RCS adjusted for age, but not when other factors were taken into account. Lagging employment histories by 15 years gave rise to no apparent trend. Only two deaths occurred from pneumoconiosis; both were dry/dryer workers at quarry 6. Unspecified pneumoconiosis was mentioned as a contributory cause to two other deaths of dry/dryer workers at the same quarry. The average age at hire of all four cases was just over 40 , and the average length of employment 10 years. This is only one extra case (death from silicosis) in the 14 years of extra follow up since the original HSE analysis, and it was said then that the cases were related to previous exposure to coal dust, but this could not be verified, as previous job histories were unknown. From the experience of the work on US sand workers we would have expected more cases of silicosis based on the cohort size. Steenland and Sanderson ${ }^{16}$ observed 11 cases of silicosis or silico-tuberculosis in a cohort of 4625 workers, and McDonald and her colleagues ${ }^{17}$ observed 37 cases in a cohort of 2670 workers, based on the average exposure to RCS in the cohort. This information might have been available from individual medical records, but gaining permission to examine these would have been very difficult. Reasons why only two cases were observed in this study include: (1) silicosis is rarely mentioned on the death certificate of people in the UK, even as a contributory cause of death; or (2) the mortality rate is actually low, and silica exposure levels were too low to have had any effect. The two deaths from pneumoconiosis were in the highest exposure category as well as one of the mentioned cases, the other being in the second highest category. This is reassuring, indicating that the exposure assessment methodology used in this study is robust.

Lung cancer mortality among men was approximately the same as expected when compared to national rates, but was raised in women (on the basis of four cases). No job category showed any significant increases in mortality from lung cancer, and although a small excess was seen among dry/ dryer workers, similar increases were not universally seen among those workers in jobs with known high RCS exposures.

Among the quarry groups a significant deficit of lung cancer was observed at quarry 4 , and a significant excess was observed at quarry 7. A potential weakness of the study was the lack of data on smoking habits for the cohort, which would normally be very important for the study of lung cancer. Smoking also plays a major role in the aetiology of circulatory and non-malignant respiratory diseases. From the analyses a reduction in mortality from these diseases was observed. Although smoking information was lacking, these results suggest it did not play a significant role in mortality within the cohort.

Further analysis of the lung cancer cases at quarry 7 showed similar results to those as the bladder cancer above, in that those who first started work between 1950 and 1959 and were employed for less than five years were at a significantly greater risk. However, there was no relation to cumulative exposure to RCS. Similarly, it might be that exposure to other pollutants at the quarry might have given rise to the increased mortality at that site and needs further investigation. In addition, the geology of the quarries and chemical composition of the sand, the different methods of extraction and refining, and whether exposure was to aged or freshly cut surfaces of silica may all have contributed to the different results between the quarries, and merits further investigation.

Examinations of lung cancer mortality did not reveal any specific patterns, with regard to job category (low numbers 
involved). The HSE WATCH Committee ${ }^{19}$ stated that "occupational exposure to freshly cut surfaces of crystalline silica will pose greater health risks than exposure to 'aged' surfaces". They also concluded "there would be a greater risk of silicosis...", and probably lung cancer, "...in workers exposed to very fine particles of crystalline silica, such as might be found in silica flours (produced at quarry 6), compared to equal masses of larger size respirable particles". Taking these criteria into consideration, at quarries 5 and 6 where freshly cut surfaces are being produced when the sand is extracted from the rock face in the quarry and during the milling process at quarry 6, the risk of silicosis and lung cancer might be greater than expected. However, mortality at these quarries was slightly less than expected, compared to other quarries.

For RCS to be categorised as a carcinogen an exposureresponse relation is one of the criteria that must be demonstrated. ${ }^{20}$ McDonald and colleagues ${ }^{17}$ observed lung cancer SMRs to increase with time since hire, but not with length of employment. Steenland and Sanderson ${ }^{16}$ also did not show any consistent trend with duration of employment, although SMRs were increased for those with less than six months' employment, and those with 10-20 years' and 20 or more years' employment. In this UK study, lung cancer mortality was significantly increased in those employed for less than five years, and then decreased to be lowest in those with 20 or more years of service.

Steenland and Sanderson ${ }^{16}$ showed a non-significant positive trend of standardised rate ratios for cumulative exposure, lagged 15 years. In a nested case-control analysis, after exclusion of short term workers, odds ratios (OR) by quartile of cumulative exposure ( 15 year lag) showed a nonsignificant positive trend, whereas ORs by average exposure showed a significant trend. In a nested case-control of the cohort studied by McDonald and colleagues, ${ }^{17}$ lung cancer mortality was related to cumulative RCS exposure and to average RCS concentration. ${ }^{11}$ In this UK study the relative risk for lung cancer did not show any trend with increasing cumulative exposure to RCS, even after lagging employment history by 15 years. Interestingly, the average silica exposure levels were higher than those in US sand workers, although not as high as those in other industrial environments where silica occurs.

No industrial hygiene data were available for the period 1950-78, and various extrapolation methods had to be used to estimate exposure levels for this period, based on data collected after 1978. Sensitivity analyses showed that although the magnitude of individual estimates varied, the patterns of mortality remained the same. The two cases of pneumoconiosis occurred in the highest exposure category. This is reassuring, indicating that the exposure assessment methodology used in this study is robust.

The various assumptions made and the limitations of the available data used to create the JEM could have resulted in some exposure misclassification. However, the use of regression lines to estimate historical exposure, inaccuracy of some job histories, and the allocation of incorrect job titles to some individuals are similar limitations encountered in other studies that attempt to estimate historical exposure, and would not affect the dose-response relation internally, but would affect the risk assessment. In addition, and like the majority of other studies, we did not take into account the use of respiratory protective equipment in the exposure assessment. Although some misclassification may have occurred, the use of quantitative measures of exposure is an improvement on qualitative estimates of exposure.

Epidemiological evidence linking crystalline silica exposure and lung cancer risk remains inconsistent. Risk estimates for lung cancer are variable between industries, and exposure-response results are not always consistent or in the same direction. To an extent, some of this variability can be explained by confounding factors-that is, smoking and other occupational exposures. Of the many studies reviewed by the IARC Working Group, ${ }^{12}$ excluding those of registered silicotics, nine were identified as providing the least confounded evidence. ${ }^{21-33}$ Four of these studies showed a clear excess cancer risk, whereas the other five showed a negative or equivocal risk. Nevertheless, the IARC Working Group commented that in view of the relatively large number of studies that have been undertaken and, given the wide range of populations and exposure circumstances, some nonuniformity of results would be expected.

However, a pooled analysis following the IARC review by Steenland and colleagues ${ }^{34}$ supported the decision by the IARC and suggested that the current exposure limits in many countries may be inadequate. They found the log of cumulative exposure, with a 15 year lag, was a strong predictor of lung cancer with consistency across studies. Results were also consistent between underground mines and other facilities. Categorical analysis by quintile of cumulative exposure resulted in a positive monotonic exposure-response trend. They estimated the excess lifetime risk of lung cancer for a worker exposed from age 20 to 65 at $0.1 \mathrm{mg} / \mathrm{m}^{3}$ RCS was $1.1-1.7 \%$, above background risks of $3-6 \%$.

If RCS is linked with an excess of lung cancer risk, an important question is whether this risk is limited to those individuals with silicosis. In a study of Western Australian gold miners, it was concluded that excess lung cancer risk did not occur in the absence of silicosis, ${ }^{35}$ whereas a recent review of the evidence came to the opposite conclusion. ${ }^{36}$ Lung cancer risk in this UK study was not greater than expected, and there was only one confirmed death from silicosis, one from unspecified pneumoconiosis, and two as contributory causes. Therefore, these findings tend to support the premise that in the absence of an increase in mortality from silicosis lung cancer risk is not increased.

In conclusion, this study has not shown any consistent relation between respirable crystalline silica exposure, in the absence of other known carcinogens, and the development of lung cancer in the UK silica sand industry whose exposure levels are relatively low compared to studies in other industries. This contrasts with a series of studies which have shown positive findings in similar and related industries and positive studies in animals which led IARC to classify silica as a carcinogen to humans. ${ }^{12}$ However, as can be seen in table 1 , the cohort is still relatively young and further follow up of the cohort is planned. The possibility of including individuals who started work with the company after 1986, and also for whom measurement data will be available investigating the availability of medical information such as $x$ rays is being considered. A nested case-control study of the lung cancer cases is also being considered, in which more detail on work, exposure, and medical histories would be obtained.

\section{ACKNOWLEDGEMENTS}

The authors would like to thank the European Association of Industrial Silica Producers (EUROSIL) for funding this study. We would like to thank the Health and Safety Executive for providing the cohort data and staff at the company involved for their assistance in updating personal and job histories and commenting on the technical aspects of silica sand production.

\section{Authors' affiliations}

T P Brown, L Rushton, Medical Research Council Institute for Environment and Health, 94 Regent Road, Leicester, LE1 7DD, UKMedical Research Council Institute for Environment and Health, Leicester, UK

Competing interests: none declared 


\section{REFERENCES}

1 Muir DCF, Shannon HS, Julian JA, et al. Silica exposure and silicosis amon Ontario hardrock miners: I. Methodology. Am J Ind Med 1989;16:5-11.

2 Muir DCF, Julian JA, Shannon HS, et al. Silica exposure and silicosis among Ontario hardrock miners: III. Analysis and risk estimates. Am J Ind Med 1989; 16:29-43.

3 Muir DCF. Correction in cumulative risk in silicosis exposure assessment [letter]. Am J Ind Med 1991; 19:555.

4 Hnizdo E, Murray J, Sluis-Cremer GK, et al. Correlation between radiological and pathological diagnosis of silicosis: an autopsy population based study. Am J Ind Med 1993;24:427-45.

5 Hnizdo E, Sluis-Cremer G. Risk of silicosis in a cohort of white South African gold miners. Am J Ind Med 1993;24:447-57.

6 Steenland K, Brown D. Silicosis among gold miners: exposure-response analyses and risk assessment. Am J Public Health 1995;85:1372-7.

7 Banks DE. Clinical features of silicosis. In: Castranova V, Vallyathan V, Wallace WE, eds. Silica and silica-induced lung diseases. Boca Raton, FL: CRC Press Inc, 1996:23-37.

8 Rosenman KD, Reilly MJ, Rice C, et al. Silicosis among foundry workers. Implication for the need to revise the OSHA standard [abstract]. Am J Epidemiol 1996;144:890-900.

9 American Thoracic Society. Adverse effects of crystalline silica exposure. Am J Respir Crit Care Med 1997; 155:761-768.

10 Hughes JM, Weill H, Checkoway H, et al. Radiographic evidence of silicosis risk in the diatomaceous earth industry. Am J Respir Crit Care Med 1998;158:807-14

11 Hughes JM, Weill H, Rando RJ, et al. Cohort mortality study of North American industrial sand workers. II. Case-referent analysis of lung cancer and silicosis deaths. Ann Occup Hyg 2001;45:201-7.

12 IARC. Silica, some silicates, coal dust and para-aramid fibrils. Lyon: International Agency for Research on Cancer, 1997.

13 Brown TP, Rushton L. Mortality in the UK industrial silica sand industry: 1. Assessment of exposure to respirable crystalline silica. Occup Environ Med 2005;62:442-5.

14 University of Pittsburgh. OCMAP-Plus v3.09. Pittsburgh, PA: Department of Biostatistics, University of Pittsburgh, 2002.

15 StataCorp. Stata statistical software. College Station, TX: Stata Corporation 2001

16 Steenland K, Sanderson WT. Lung cancer among industrial sand workers exposed to crystalline silica. Am J Epidemiol 2001;153:695-703.

17 McDonald AD, McDonald JC, Rando RJ, et al. Cohort mortality study of North American industrial sand workers. I. Mortality from lung cancer, silicosis and other causes. Ann Occup Hyg 2001; 45: 193-9.

18 Benn RT, Hutchings SJ, Thomas PG, et al. Mortality of workers in the silica sand industry. Unpublished results, 1991.

19 HSE. Working Group on the Assessment of Toxic Chemicals (WATCH). Crystalline silica: Phase 1. London: Health \& Safety Executive, 2001.
20 Hill $\mathbf{A B}$. The environment and disease: association or causation? Proc $R$ Soc Med 1965;58:295-300.

21 Costello J, Graham WGB. Vermont granite worker's mortality study. Am J Ind Med 1988;13:483-97.

22 Guenel P, Hojberg G, Lynge E. Cancer incidence among Danish stone workers. Scand J Work Environ Health 1989;15:265-70.

23 Winter PD, Gardner MJ, Fletcher AC, et al. A mortality follow-up study of pottery workers: preliminary findings on lung cancer. In: Simonato $\mathrm{L}$, Fletcher AC, Saracci R, et al, eds. Occupational exposure to silica and cancer risk. Lyon: International Agency for Research on Cancer, 1990:83-94.

24 Merlo F, Costantini M, Reggiardo $G$, et al. Lung cancer risk among refractory brick workers exposed to crystalline silica: a retrospective cohort study. Epidemiology 1991;2:299-305.

25 Mclaughlin JK, Jing-Qiong C, Dosemeci M, et al. A nested case-control study of lung cancer among silica exposed workers in China. $\mathrm{Br} J$ Ind Med 1992:49:167-71.

26 Checkoway H, Heyer NJ, Demers PA, et al. Mortality among workers in the diatomaceous earth industry. Br J Ind Med 1993;50:586-97.

27 Costello J, Castellan RM, Swecker GS, et al. Mortality of a cohort of U.S workers employed in the crushed stone industry, 1940-1980. Am J Ind Med 1995;27:625-40.

28 Dong $D, X u G$, Sun $Y$, et al. Lung cancer among workers exposed to silica dust in Chinese refractory plants. Scand J Work Environ Health 1995:21(suppl 2):69-72.

29 Checkoway H, Heyer NJ, Demers PA, et al. Reanalysis of mortality from lung cancer among diatomaceous earth industry workers, with consideration of potential confounding by asbestos exposure. Occup Environ Med 1996;53:645-7.

30 Burgess GL, Turner S, McDonald JC, et al. Cohort mortality study of Staffordshire pottery workers: (I) Radiographic validation of an exposure matrix for respirable silica. Ann Occup Hyg 1997:41:403-7.

31 Cherry NM, Burgess GL, Turner S, et al. Cohort study of Staffordshire pottery workers: (II) Nested case referent analysis of lung cancer. Ann Occup Hyg 1997;41:408-11.

32 McDonald JC, Burgess GL, Turner S, et al. Cohort study of Staffordshire pottery workers: (III) lung cancer, radiographic changes, silica exposure and smoking habit. Ann Occup Hyg 1997;41:412-14.

33 Chen J, McLaughlin JK, Zhang J-Y, et al. Mortality among dust-exposed Chinese mine and pottery workers. J Occup Med 1992;34:311-16.

34 Steenland K, Mannetje A, Boffeta P, et al. Pooled exposure-response analyses and risk assessment for lung cancer in 10 cohorts of silica-exposed workers: an IARC multicentre study. Cancer Causes Control 2001;12:773-84.

35 de Klerk NH, Musk AW. Silica, compensated silicosis, and lung cancer in Western Australian goldminers. Occup Environ Med 1998;55:243-8.

36 Checkoway $\mathbf{H}$, Franzblau A. Is silicosis required for silica-associated lung cancer? Am J Ind Med 2000;37:252-9. 